\title{
Growth and enterotoxin production of Bacillus cereus in cow, goat, and sheep milk
}

\author{
Lenka Necidová1, Šárka Bursová1, Alena Skočková1, Bohdana Janštová2

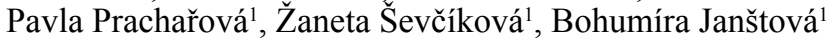

University of Veterinary and Pharmaceutical Sciences Brno, Faculty of Veterinary Hygiene and Ecology, ${ }^{1}$ Department of Milk Hygiene and Technology, ${ }^{2}$ Department of Vegetable Foodstuffs Hygiene and Technology, Brno, Czech Republic

Received July 21, 2014

Accepted November 26, 2014

\begin{abstract}
The aim of this study was to compare Bacillus cereus growth rates and diarrhoeal enterotoxin production in raw and pasteurized goat, sheep, and cow milk in terms of storage conditions. Milk samples were inoculated with B. cereus (CCM 2010), which produces diarrhoeal enterotoxins. Enterotoxin production was tested by ELISA (Enzyme-Linked Immunosorbent Assay), and the count of $B$. cereus was determined by the plate method. With raw cow milk, B. cereus growth and enterotoxin production can be completely suppressed; in raw goat and sheep milk, enterotoxin was produced at $22^{\circ} \mathrm{C}$. In pasteurized cow, goat, and sheep milk, the B. cereus count increased under all storage conditions, with more rapid growth being observed at $15^{\circ} \mathrm{C}$ (sheep milk) and $22^{\circ} \mathrm{C}$ (cow and goat milk). Enterotoxin presence was detected at $15^{\circ} \mathrm{C}$ and $22{ }^{\circ} \mathrm{C}$, and with pasteurized cow milk also at $8^{\circ} \mathrm{C}$. Our model experiments have determined that $B$. cereus multiplication and subsequent enterotoxin production depend on storage temperature and milk type.
\end{abstract}

Food safety, diarrhoeal enterotoxins, raw milk, pasteurized milk

The high level of nutrients in milk makes it an especially suitable growth medium for bacteria. In fact, these microorganisms can achieve high population densities following contamination during milk processing. In particular, contamination of milk by members of the Bacillus cereus group is of significance, not only because of their spoilage capability, but also because of their potential to cause human diseases (Janštová et al. 2006; Bartoszewicz et al. 2008). Svensson et al. (2007) in their study have assumed that the mesophilic isolates of $B$. cereus from the farm, silo tanks, and pasteurized milk are often high producers of enterotoxin. Major sources of B. cereus in pasteurized milk are spores in raw milk (Lin et al. 1998).

Bacillus cereus can grow in most foods at a $\mathrm{pH}$ above 4.5 and temperatures above $4{ }^{\circ} \mathrm{C}$ (van-Netten et al. 1990; Granum 2005). Storage temperature is an important factor in order to keep the B. cereus number low. At a dairy, milk is generally kept at $4{ }^{\circ} \mathrm{C}$, which helps to assure longevity. During distribution, however, temperatures of up to $8{ }^{\circ} \mathrm{C}$ are common. Furthermore, the consumer often exposes milk to higher temperatures. The increase in numbers of $B$. cereus is tremendous when the storage temperature is elevated by just $2^{\circ} \mathrm{C}$, from $6^{\circ} \mathrm{C}$ to $8^{\circ} \mathrm{C}$ (Andersson et al. 1995).

There are two different types of $B$. cereus food poisoning. The first type caused by an emetic toxin results in vomiting; the second type caused by one of three different enterotoxins induces diarrhoea (Granum 2001; Svensson et al. 2004). Diarrhoeal syndrome incubation period is $8-16 \mathrm{~h}$, and duration of illness is $12-24 \mathrm{~h}$. The symptoms are abdominal pain, watery diarrhoea, sometimes with nausea (Granum 1994, 2000, 2001). The total infective dose for diarrhoeal syndrome seems to vary between about $10^{5}$ and $10^{7}$ viable cells or spores. Thus, any food containing more than $10^{3} \mathrm{~B}$. cereus $\cdot \mathrm{g}^{-1}$ can not be considered completely safe for consumption (Granum et al. 1997). The variation in 
the infective dose may be due to the ability of different strains to produce enterotoxin and to different susceptibilities of individuals (Granum et al. 2000). The Czech Standard ČSN 569609 (2005) sets the maximum limit values of $10^{5} \mathrm{CFU} \cdot \mathrm{ml}^{-1}\left(\log 5.00 \mathrm{CFU} \cdot \mathrm{ml}^{-1}\right)$ of $B$. cereus for foods not intended for direct consumption and $10^{4} \mathrm{CFU} \cdot \mathrm{ml}^{-1}(\log 4.00$ $\mathrm{CFU} \cdot \mathrm{ml}^{-1}$ ) for foods intended for direct consumption. The diarrhoeal toxins may be produced by psychrotrophic strains at temperatures down to $4{ }^{\circ} \mathrm{C}$ (Granum et al. 2000).

The aim of this study was to compare the growth rates of $B$. cereus and diarrhoeal enterotoxin production in raw and pasteurized goat, sheep, and cow milk in terms of varying storage conditions.

\section{Materials and Methods}

Bacillus cereus strain CCM 2010 producing enterotoxins was obtained from the Czech Collection of Microorganisms (Brno, Czech Republic). Cow, goat and sheep milk singular samples were investigated, both raw and pasteurized. Raw cow milk samples were obtained from a milk vending machine, and goat and sheep milk samples came from farms. Pasteurization was carried out at $75{ }^{\circ} \mathrm{C}$ for $20 \mathrm{~s}$. Milk samples negative for B. cereus were inoculated with $\log 3.00-4.74 \mathrm{CFU} \cdot \mathrm{ml}^{-1}$ of $B$. cereus CCM 2010 . Inoculated milk samples were incubated at $8{ }^{\circ} \mathrm{C}, 15^{\circ} \mathrm{C}$, and $22{ }^{\circ} \mathrm{C}$ for seven days to simulate inappropriate transport and storage conditions. The cultures were sampled on days 0-4 and 7. During the incubation, $\mathrm{pH}$ of the model samples was measured. Enumeration of B. cereus was performed using the Manitol Yolk Polymyxin B agar (Oxoid, Basingstoke, GB) plate count method in accordance with ČSN EN ISO 7932 (2005), and the plates were incubated aerobically at $30{ }^{\circ} \mathrm{C}$ for $24 \mathrm{~h}$. To detect enterotoxins, the Diarrhoeal Enterotoxin Visual ImmunoAssay (TECRA, Roseville New South Wales, Australia) was used following the manufacturer's instructions.

\section{Results}

Our experiments revealed variation in $B$. cereus counts during the culture period and in the time to enterotoxin production, depending on the storage conditions and type of milk.

In raw cow milk inoculated with $B$. cereus at $\log 3.70 \mathrm{CFU} \cdot \mathrm{ml}^{-1}$, stored at $8{ }^{\circ} \mathrm{C}, 15^{\circ} \mathrm{C}$, and $22{ }^{\circ} \mathrm{C}$, the bacterium count decreased to $<\log 0.69 \mathrm{CFU} \cdot \mathrm{ml}^{-1}$ after $24 \mathrm{~h}$ and remained so during the entire experiment. No enterotoxin production was detected (Table 1). As $B$. cereus was not detected in raw cow milk at a $\mathrm{pH}$ of 6.59 , where pasteurized milk was positive for $B$. cereus and enterotoxin, we conclude that $B$. cereus growth is influenced not by $\mathrm{pH}$ count but by competitive microbiota not present in pasteurized milk.

Table 1. Time to the first detection of Bacillus cereus enterotoxins in different types of milk

\begin{tabular}{|c|c|c|c|c|c|c|}
\hline \multirow{4}{*}{ Type of milk } & \multicolumn{3}{|c|}{ Raw milk } & \multicolumn{3}{|c|}{ Pasteurized milk } \\
\hline & \multicolumn{6}{|c|}{ Storage temperature } \\
\hline & $8^{\circ} \mathrm{C}$ & $15^{\circ} \mathrm{C}$ & $22^{\circ} \mathrm{C}$ & $8^{\circ} \mathrm{C}$ & $15^{\circ} \mathrm{C}$ & $22^{\circ} \mathrm{C}$ \\
\hline & \multicolumn{6}{|c|}{ Day of storage } \\
\hline Cow milk & - & - & - & 7 & 2 & 1 \\
\hline Goat milk & - & - & 1 & - & 2 & 1 \\
\hline Sheep milk & - & - & 4 & - & 4 & 1 \\
\hline
\end{tabular}

Fig. 1 records the increase in the $B$. cereus count in pasteurized cow milk. At both $15^{\circ} \mathrm{C}$ and $22^{\circ} \mathrm{C}$, the recommended limit of $\log 4.00 \mathrm{CFU} \cdot \mathrm{ml}^{-1}$ (ČSN 569609, 2008) was exceeded prior to $24 \mathrm{~h}$ of storage. Storage temperature significantly influences the growth of $B$. cereus and enterotoxin production in pasteurized cow milk (Table 1).

In raw goat milk stored specifically at $15{ }^{\circ} \mathrm{C}$ and $22^{\circ} \mathrm{C}$, the recommended limit of $\log$ $5.00 \mathrm{CFU} \cdot \mathrm{ml}^{-1}$ (ČSN 569609, 2008) was exceeded prior to $24 \mathrm{~h}$ of storage. No enterotoxin production was detected in raw goat milk stored at $8{ }^{\circ} \mathrm{C}$ and $15{ }^{\circ} \mathrm{C}$, although enterotoxin was detected after $24 \mathrm{~h}$ in milk stored at $22{ }^{\circ} \mathrm{C}$ (Table 1). Fig. 2 shows a higher overall 


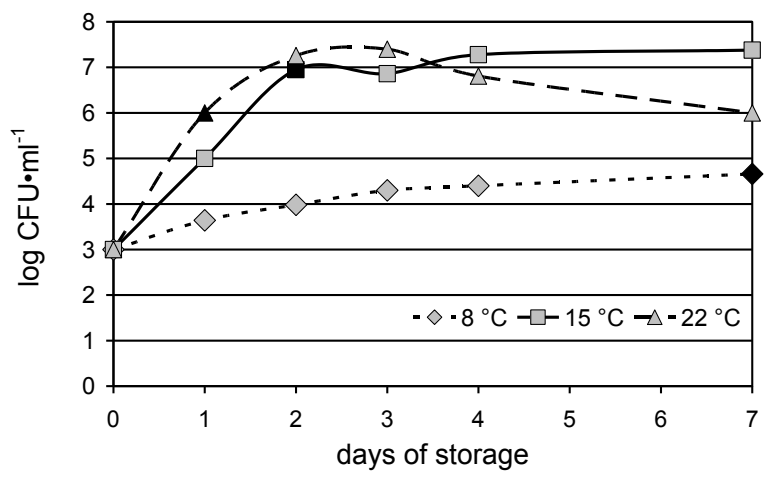

Fig. 1. Bacillus cereus growth in pasteurized cow milk

Note: The black shapes indicate the first detection of enterotoxins

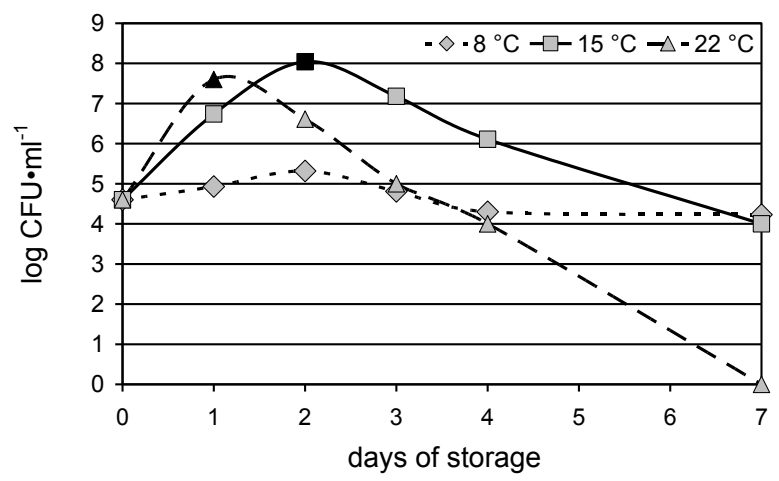

Fig. 2. Bacillus cereus growth in pasteurized goat milk

Note: The black shapes indicate the first detection of enterotoxins

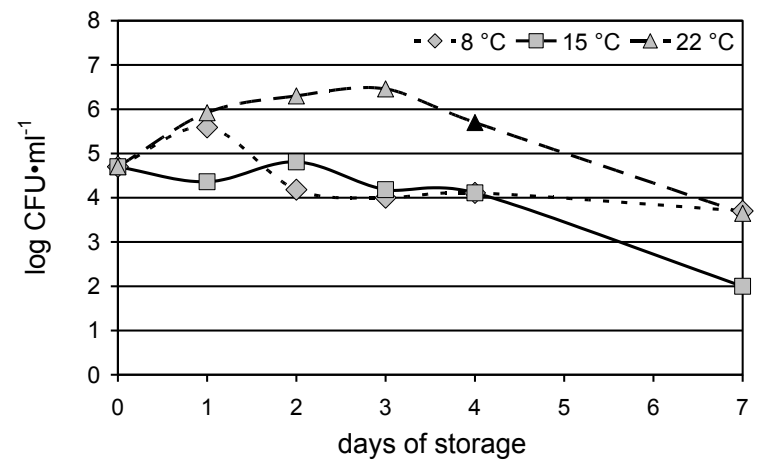

Fig. 3. Bacillus cereus growth in raw sheep milk

Note: The black shapes indicate the first detection of enterotoxins 


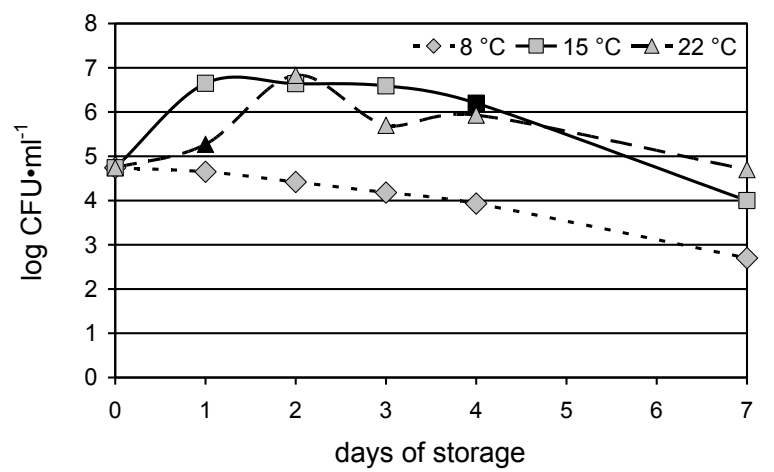

Fig. 4. Bacillus cereus growth in pasteurized sheep milk

Note: The black shapes indicate the first detection of enterotoxins

B. cereus count at $15^{\circ} \mathrm{C}$ and at $22^{\circ} \mathrm{C}$. Presence of enterotoxin was detected after 2 days in pasteurized goat milk stored at $15^{\circ} \mathrm{C}$ and within $24 \mathrm{~h}$ in pasteurized goat milk stored at $22{ }^{\circ} \mathrm{C}$ (Table 1$)$.

Figs 3 and 4 show $B$. cereus growth in both raw and pasteurized sheep milk. Table 1 indicates detection of enterotoxin in raw sheep milk after 4 days of storage at $22{ }^{\circ} \mathrm{C}$. At $15^{\circ} \mathrm{C}$, enterotoxin was detected in pasteurized sheep milk after 4 days of storage, although at $22{ }^{\circ} \mathrm{C}$, enterotoxin was detected prior to $24 \mathrm{~h}$ of storage.

\section{Discussion}

According to Christiansson (1993), the number of B. cereus present in food must be at least $10^{6} \cdot \mathrm{g}^{-1}$ or $\mathrm{ml}^{-1}$, and sufficiently high amounts of enterotoxin must be formed, to survive the $\mathrm{pH}$ of stomach and the proteolytic enzymes of the duodenum (Granum 1994; Granum et al. 2000). Granum (2005) has also reported that the growth of B. cereus is prevented with a $\mathrm{pH}$ below 4.5 . This is confirmed in part by our results showing a rapid decrease in $\mathrm{pH}$ below 4.5 in raw cow milk stored at higher temperatures, with $B$. cereus growth being inhibited.

In contrast to raw cow milk, $B$. cereus multiplied in raw goat and sheep milk at $8{ }^{\circ} \mathrm{C}$ within the first $24 \mathrm{~h}$, with its count only showing a slight downward trend during the entire storage period. Although the limit of $\log 5.00 \mathrm{CFU} \cdot \mathrm{ml}^{-1}$ was exceeded in isolated cases, toxin production was not detected. In raw goat milk at higher temperatures, natural competitive microbiota and decreased $\mathrm{pH}$ quickly inhibited $B$. cereus growth. The initial sharp rise of $B$. cereus counts at $22{ }^{\circ} \mathrm{C}$ was high enough to produce enterotoxins. The increase in $B$. cereus count in sheep milk was considerably higher at $22^{\circ} \mathrm{C}$ than at $15^{\circ} \mathrm{C}$, but the opposite was true for both goat and cow milk. A possible explanation for this phenomenon could be a different composition of sheep milk natural microbiota and a slower $\mathrm{pH}$ drop that might have been influenced by $B$. cereus proteolytic activity. Our results indicate that unlike cow milk, raw goat milk and particularly sheep milk are better substrates for multiplication of $B$. cereus where enterotoxins may be produced at higher storage temperatures.

Previous studies also noted that $B$. cereus growth in raw cow milk is very low and that higher numbers of $B$. cereus are detected in pasteurized and heat-treated milk (Svensson et al. 2004; Adams et al. 2008). Pasteurized milk was a good substrate for enterotoxin production. In pasteurized sheep and goat milk stored at $8{ }^{\circ} \mathrm{C}$, no enterotoxin production was detected, even when the $B$. cereus count increased above the recommended limit of log 
4.00 CFU $\cdot \mathrm{ml}^{-1}$. Although Andersson et al. (1995) have reported that there are strains of $B$. cereus that may cause food poisoning with an infective dose as low as $10^{3}-10^{4}$ bacteria/ gram, our results are rather consistent with the conclusion of Langeveld et al. (1996) that there is no evidence that $B$. cereus concentrations less than $10^{5} \cdot \mathrm{ml}^{-1}$ cause intoxication. In pasteurized cow's milk stored at $8{ }^{\circ} \mathrm{C}$, the presence of diarrhoeal enterotoxin was detected after 7 days. At higher storage temperatures, B. cereus counts rose sharply in pasteurized milk of all types, considerably exceeding the limit of $\log 4.00 \mathrm{CFU} \cdot \mathrm{ml}^{-1}$, which was associated with enterotoxin production. Therefore, we conclude that maintaining the cold chain at $8{ }^{\circ} \mathrm{C}$ or less, in accordance with the legislation in force (Decree No. 77/2003), and consuming milk within seven days minimizes the risk of $B$. cereus diarrhoeal enterotoxin. According to Andersson et al. (1995), with a low number of spores in the products and proper cooling (at least not exceeding the temperature of $6^{\circ} \mathrm{C}$ ), B. cereus food poisoning through milk and milk products can be avoided, as very few strains grow at $6{ }^{\circ} \mathrm{C}$ and below.

Our model experiment results have determined that B. cereus multiplication and subsequent enterotoxin production depend on storage temperature and type of milk. Pasteurized milk is a more suitable substrate for B. cereus multiplication and enterotoxin production than raw milk. With raw cow milk in contrast with sheep and goat milk, $B$. cereus growth and enterotoxin production are more markedly suppressed by competitive microbiota. Nevertheless, this finding should not be interpreted as a reason to encourage consumption of raw, unpasteurized milk. Finally, our study results reinforce the importance of maintaining the cold chain (at a safe temperature under $8^{\circ} \mathrm{C}$ ) from production through retail sale to insure safety of milk and dairy products.

\section{Acknowledgement}

The study was supported by research grants MSM 6215712402 Veterinary Aspects of Food Safety and Quality, and IGA VFU 16/2013/FVHE.

\section{References}

Adams MR, Moss MO 2008: Bacillus cereus and other Bacillus species. In: Adams MR, Moss MO (Eds): Food Microbiology, $3^{\text {rd }}$ edn. Royal Society of Chemistry, Cambridge, pp. 185-190

Andersson A, Ronner U, Granum PE 1995: What problems does the food industry have with the spore-forming pathogens Bacillus cereus and Clostridium perfringens? Int J Food Microbiol 28: 145-155

Bartoszewicz M, Hansen BM, Swiecicka I 2008: The members of the Bacillus cereus group are commonly present contaminants of fresh and heat-treated milk. Food Microbiol 25: 588-596

Christiansson A 1993: Enterotoxin production in milk by Bacillus cereus: a comparison of methods for toxin detection. Neth Milk Dairy 47: 79-87

ČSN 569609 2008: Guide to good hygiene and manufacturing practise - Microbiological criteria for foods. Principles for establishment and application (in Czech), $40 \mathrm{p}$.

ČSN EN ISO 7932 2005: Microbiology of food and animal feeding stuffs - Horizontal method for the enumeration of presumptive Bacillus cereus - Colony-count technique at $30^{\circ} \mathrm{C}$ (in Czech), $20 \mathrm{p}$

Decree No 77 of 6 March 2003 laying down the requirements for milk, dairy products, ice creams, and edible fats and oils. Code, 2003, part 32, pp. 2488-2516

Granum PE 1994: Bacillus cereus and its toxins. J Appl Bacteriol Suppl 76: 61S-66S

Granum PE, Lund T 1997: Bacillus cereus and its food poisoning toxins. FEMS Microbiol Lett 157: 223-228

Granum PE, Baird-Parker TC 2000: Bacillus spp. In: Lund B, Baird-Parker TC, Gould GW (Eds): The microbiological safety and quality of food. Aspen Publishers MD, USA, pp. 1029-1039

Granum PE 2001: Bacillus cereus. In: Doyle MP, Beuchat LR, Montville (Eds): Food Microbiology, $2^{\text {nd }}$ edn. Fundamentals and Frontiers. ASM Press, Washington DC, pp. 373-381

Granum PE 2005: Bacillus cereus. In: Fratamico PM, Bhunia AK, Smith JL (Eds): Foodborne Pathogens: Microbiology and Molecular Biology. Caister Academic Press, Norfolk, pp. 409-419

Janštová B, Dračková M, Vorlová L 2006: Effect of Bacillus cereus enzymes on the milk quality following ultra high temperature processing. Acta Vet Brno 75: 601-609

Langeveld LPM, van Spronsen WA, van Beresteijn ECH, Notermans SHV 1996: Consumption by healthy adults of pasteurized milk with a high concentration of Bacillus cereus: A double-blind study. J Food Protect 59: 723-726 
Lin S, Schraft H, Odumeru JA, Griffiths MW 1998: Identification of contamination sources of Bacillus cereus in pasteurized milk. Int J Food Microbiol 43: 159-171

Svensson B, Ekelund K, Ogura H, Christiansson A 2004: Characterisation of Bacillus cereus isolated from milk silo tanks at eight different dairy plants. Int Dairy J 14: 17-27

Svensson B, Monthán A, Guinebretière MH, Nguyen-Thé C, Christiansson A 2007: Toxin production potential and the detection of toxin genes among strains of the Bacillus cereus group isolated along the dairy production chain. Int Dairy J 17: 1201-1208

van Netten P, van de Moosdijk A, van de Hoensel P, Mossel DA, Perales I 1990: Psychrotrophic strains of Bacillus cereus producing enterotoxin. J Appl Bacteriol 69: 73-79 